\title{
Panik Bozukluğu Hastalarında Uykuda Kalp Hızı Değişskenliği
}

\section{Heart Rate Variabilty During Sleep in Patients with Panic Disorders}

\author{
Sinan Yetkin, Aykut Erdamar*, Mehmet Yokuşoğlu**, Fuat Özgen***, Hamdullah Aydın**** \\ Gülhane Askeri Tıp Fakültesi, Psikiyatri Anabilim Dalı, Ankara, Türkiye \\ *Başkent Üniversitesi, Biyomedikal Mühendisliği Bölümü, Ankara, Türkiye \\ **Gülhane Askeri Tıp Fakültesi, Kardiyoloji Anabilim Dalı, Ankara, Türkiye \\ ***Bayındır Hastanesi, Psikiyatri Kliniği, Ankara, Türkiye \\ ****Uyku Günlügü, Uyku Araştırma Merkezi, Ankara, Türkiye
}

\section{Özet}

Giriş: Çalışmalar genel olarak panik bozukluğunda azalmış vagal tonus ve göreceli olarak artmış hakimiyetin olduğu, azalmış kalp hızı değişkenliğini (KHD) işaret etmektedir. Gündüz çalışmaları panik bozukluğu hastalarında daha tutarlı şekilde düşük kalp hızı değişkenliğini sonucu verirken, uykuda KHD çalışmaları çelişkili sonuçlar vermektedir. Bu nedenle, panik bozukluğu hastalarında polisomnografi kayıtlarını kullanarak kardiyak otonomik işlevin araştırılması amaçlanmıştır.

Gereç ve Yöntem: On beş tedavi almayan panik bozukluğu hastası ve 15 yaş ve cinsiyet yönünden eşleştirilmiş normal kontrol grubu ardışık iki gece polisomnografi kaydı ile çalışı ııştır. Analiz için ikinci gece kayıtları alınmıştır.

Bulgular: Hastalar düşük uyku etkinliği, artmış uyanıklık sayısı ve uzamış uyku latansı göstermekteydi. Panik bozukluğu ve kontrol grubu arasında zaman ve frekans-alan KHD değişkenleri karşılaştıııldığında istatistiksel olarak anlamlı bir fark elde edilememiştir.

Sonuç: Bu sonuç tedavi almayan hastalığın erken dönemindeki panik bozukluğu hastalarında sempatovagal dengenin etkilenmemiş olabileceğini işaret etmektedir. (JTSM 2014;1:28-32)

Anahtar Kelimeler: Panik bozukluk, kalp hızı değişkenliği, otonom sinir sistemi, uyku, spektral analiz

\section{Summary}

Introduction: Studies generally indicate that panic disorder patients have reduced heart rate variability (HRV), diminished vagal tone and relative sympathetic dominance. Despite a consistent profile of reduced HRV in PD patients during daytime assessments, sleep-based HRV studies have yielded inconsistent results. For this reason, we aimed to investigate cardiac autonomic function in PD patients using polysomnographic records.

Materials and Methods: 15 non-medicated PD patients and 15 ageand sex-matched normal controls were studied on polysomnography on two consecutive nights. Data were extracted from the second night for analysis.

Results: Patients showed poor sleep efficiency, increased the number of the awakenings, and longer sleep latency than controls. Comparison of time domain and frequency domain HRV parameters between PD patients and control subjects revealed that there were no statistically significant differences.

Discussion: The results indicate that the sympathovagal balance might not be influenced in drug-free patients with panic disorder in the early stage of illness. (JTSM 2014;1:28-32)

Key Words: Panic disorder, heart rate variability, autonomic nervous system, sleep, spectral analysis 


\section{Giriş}

Panik bozukluk hayat kalitesini oldukça olumsuz etkileyen ve en sık görülen anksiyete bozukluklarından biridir. Hastaların panik nöbetleri sırasında yaşadıkları çarpıntı, göğüs ağrısı, nefes darlığı, soluğun kesilmesi, terleme, titreme gibi belirtiler otonom sinir sistemi ile ilişkili bulgulardır (1). Bu belirtiler otonom sinir sisteminde işlev bozukluğuna işaret eder ve bu anksiyete nöbetlerinin fizyopatolojisinde artmış sempatik aktivitenin önemli bir rol oynayabileceği kabul edilir (2).

Kalp ritminin atımdan atıma farkın değişkenliğinin analizi olan kalp hızı değişkenliği (KHD), kalbin otonomik işlevinin değerlendirilmesinde kullanılan dolaylı, ancak güvenilir bir yöntemdir. Azalmış kalp hızı değişkenliği, kardiyovasküler hastalık ve mortalite yönünden artmış riskin bir belirleyicisi olarak değerlendirilir $(3,4)$. Aynı zamanda giderek artan çalışmalar, kalp hızı değişkenliğinin duygudurum, biliş ve davranış alanlarındaki sağlıkılığın bir göstergesi olabileceğini desteklemektedir (5). Psikopatoloji ile otonomik disfonksiyon arasındaki ilişkinin incelenmesinde kalp hızı değişkenliği duyarlı bir yöntem olarak kullanılabilir.

Panik bozukluğunda kalp hızı değişkenliği çalışmalarının büyük bir bölümü kısa süreli istirahat kayıtları veya kısa süreli müdahaleler (soğuk uygulama, postür değişikliği, sodyum laktat infüzyonu veya çeşitli farmakolojik ajanlar) sonrası otonomik cevabın değerlendirildiği araştırmalardır. Genel olarak bu çalışmalarda panik bozukluğu hastalarında kalp hızı değişkenliğinin azaldığı, yani parasempatik tonusun azaldığı ve göreceli olarak sempatik hâkimiyetin oluştuğu görülmüştür (6-14) Otonomik cevabın normal olduğunu gösteren çalışmalar da mevcuttur $(15,16)$.

Kalp hızı değişkenliğinin uykuda incelenmesi, uyanıklıktaki bozucu dış faktörlerin etkisinden uzak, tonik otonomik işlevin değerlendirilmesinde daha değerli sonuçlar alınmasını sağlayabilir. Ancak panik bozukluğu hastalarında sınırlı sayıdaki uykuda kalp hızı değiş̧kenliği çalışmalarından tutarlı sonuçlar elde edilememiştir (17-20). Bu nedenle bu çalışmada ilaç kullanmayan panik bozukluğu hastalarının polisomnografi çalışması ile kalp hızı değişkenliğinin zaman ve frekans-alanında analizi amaçlanmıştır.

\section{Gereçler ve Yöntem}

\section{Denekler}

Çalışma 2001-2006 tarihleri arasında uyku çalışması yapılan ve çalışma öncesi en az iki hafta süreyle tedavi almayan panik bozukluğu olgularının kayıtları geriye dönük incelenerek yapılmıştır. Çalışma koşullarına uygun sekizi erkek, yedisi kadın toplam 15 panik bozukluğu hastasının (ortalama yaş: 27,0 04,5 ) polisomnografi kaydı değerlendirilmeye alınmıştır. Kontrol grubu için yaş ve cinsiyet olarak eşleştirilmiş altısı erkek, dokuzu

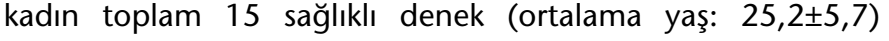
alınmıştır. Kontrol grubu uyku laboratuvarı arşivinden SCID ile psikiyatrik bozukluğu saptanmayan, tıbbi, nörolojik veya uyku bozukluğu olmayan sağlıklılardan seçilmiştir.

Hastalar klinik ve uyku laboratuvarı sorumlusu iki ayrı psikiyatrist tarafından değerlendirilerek panik bozukluğu tanısı konulan olgulardan, DSM-III-R için yarı yapılandırılmış klinik görüşme formu (SCID) uygulananlardır $(21,22)$. SCID ile halen ve geçmişte depresyon saptananlar, son iki hafta içinde psikotrop ya da alkol/ madde almış olanlar, kardiyovasküler ve diğer sistemik hastalık öyküsü bulunanlar, elektrokardiyogram (EKG) anormalliği, elektroensefalogram (EEG) anormalliği, birincil uyku bozukluğu (narkolepsi, huzursuz bacaklar sendromu, obstrüktif uyku apnesi, parasomni) olan hasta kayıtları çalışmaya alınmamıştır.

Hasta grubu DSM-IV ölçütlerine (Amerikan Psikiyatri Birliği, 1994) göre agorafobisi olmayan panik bozukluğu hastalardır. Hastaların hiç birinde gece uykuda panik nöbet mevcut değildi. Hastalığın şiddeti için Türkçe geçerliliği ve güvenirliği yapılmış panik ve agorafobi kullanılmıştır $(23,24)$. Eşlik eden psikiyatrik bozukluklar Türkçe geçerliliği ve güvenirliği olan DSM-III-R için yarı yapılandırılmış klinik görüşme formu (SCID) ile değerlendirilmiştir $(21,22)$. Hastaların dördünde (\%26) halen ve yaşam boyu sosyal fobi, ikisinde $(\% 13,3)$ halen yaygın anksiyete bozukluğu bulunmuştur. Hastaların hiçbirinde halen ve yaşam boyu majör depresyon mevcut değildi. Hastaların demografik verileri Tablo 1'de gösterilmiştir.

\section{Polisomnografi İncelemesi}

Bütün deneklerin uykuları uyku laboratuvarında standart kayıt kurallarına uygun şekilde ardışık iki gece kaydedilmiştir. Kayıtlarda dijital polisomnograf (Somnostar Alpha Series 4; Sensor Medics, Yorba Linda, CA, USA) kullanılmıştır. Birinci gece kaydında elektroensefalogram (EEG), elektrookülogram (EOG), çene elektromiyogram (EMG), elektrokardiyogram (EKG), solunum ve anterior tibial kas elektromyogramı kaydedilmiştir. İkinci gece ise sadece EEG, EOG, EKG ve çene EMG kaydı yapılmıştır. Birinci gece kaydı adaptasyon ve primer uyku bozukluklarının (uyku apne sendromu ve periyodik bacak hareketleri) değerlendirilmesi için uygulanmış, çalışma verileri ikinci gece kaydından alınmıştır. Uluslararası uyku bozuklukları sınıflandırma ölçütlerine göre apne-hipopne indeksi (AHI) ve periyodik bacak hareketleri indeksi ( $\mathrm{PBHi}$ ) 5 ve üzeri anormal olup, çalışmada dışlama ölçütü olarak kabul edilmiştir. Tüm deneklerin $\mathrm{AHI}$ ve $\mathrm{PBH}$ indeksi beşin altında bulunmuştur. Uyku kayıtları uyku tıbbı konusunda eğitimli uzmanlar tarafından Rechtschaffen ve Kales ölçütlerine göre 30 saniyelik epoklarda skorlanmıştır (25).

\section{Kalp Hızı Değişkenliği Analizi}

Kalp hızı değişkenliği analizi için ikinci gece EKG kaydı değerlendirilmiştir. Analiz için Başkent Üniversitesi Biyomedikal Mühendisliği tarafından bu çalışma için geliştirilmiş yazılım ile artefaktan ayrıştırılmış ardışık beş dakikalık segmentler kullanılmıştır. EKG kayıtları önce zaman-alan analizi sonra kardiyak otonomik kontrolü değerlendirme amacıyla frekansalan analizi yapılmıştır. Zaman ve frekans-alan değişkenleri Avrupa Kardiyoloji Topluluğu ve Kuzey Amerika Elektrofizyoloji Topluluğu çalışma grubunun kurallarına göre hesaplanmıştır (26).

Zaman-alan analizi için; NN intervalleri ile bütün $N N$ intervallerinin standart sapması (SDNN), tüm kayıttaki 5 dakikalık segmentlerde normal NN intervallerinin ortalamasının standart sapması (SDANN), ardışık normal NN intervalleri arasındaki farkların karekökü (RMSSD), 50 milisaniyeyi aşan NN intervallerinin sayısı (NN50), 50 milisaniyeyi aşan ardışık NN intervalleri arasındaki farkın yüzdesi (PNN50) hesaplanmıştır. Frekans-alan analizi için düşük frekans (LF: 0,04-0,15) ve yüksek frekans (HF: 0,15-0,5) bandı analiz edilmiştir. Ayrıca otonomik dengenin değerlendirilmesi amacıyla LF gücünün $\mathrm{HF}$ gücüne oranı (LF/HF) hesaplanmıştır. 


\section{İstatiksel Analiz}

Gruplar arasında normal dağılım gösteren değişkenler için t-testi, normal dağılım göstermeyen ve standart sapması büyük olan veriler için Mann-Whitney $U$ testi, kategorik değişkenlerin karşılaştırıması için ki-kare testi kullanıldı. Anlamlılık düzeyi $p<0,05$ olan değerler istatistiksel olarak anlamlı kabul edildi.

\section{Sonuç}

Hasta grubu ve kontrol grubu arasında yaş ve cinsiyet yönünden anlamlı bir fark mevcut değildir. Tüm denekler birinci gece çalısmasına göre uyku apnesi ve periyodik bacak hareketleri yönünden patolojik düzeyin altında değerlendirilmiştir. İkinci gece çalışmasına göre uyku değişkenleri değerlendirildiğinde; panik bozukluğu hastalarında uyku etkinliğinde düşüklük $(p=0,001)$, uyanıklık sayısında artış $(p=0,033)$, uyku latansında gecikme $(p=0,002)$, dönem 1 uyku yüzdesinde artma $(p=0,011)$ kontrol grubuna göre anlamlı bulunmuştur. Uykunun yapısı ile ilgili diğer değişkenlerde gruplar arasında anlamlı bir fark saptanmamıştır (Tablo 1).

Tüm deneklerin sinüs ritminde olduğu görülmüş ve atrial veya ventriküler aritmi dönemleri saptanmamıştır. Panik bozukluğu hasta grubu ile kontrol grubunun tüm gece EKG kayıtlarının KHD'nin zaman ve frekans-alan değişkenleri karşılaştıııldığında istatiksel yönden anlamlı fark saptanmamışıı (Tablo 2).

\section{Tartışma}

Panik bozukluğu hastalarının polisomnografi çalışması sonucu bulunan düşük uyku etkinliği, gecikmiş uyku latansı, artmış uyanıklık sayısı uykunun devamlılığının bozulduğu gözlenmiştir. Uykudaki bu sonuçlar panik bozukluğunda öncesinde yapılan çalışma sonuçları ile uyumludur (27-31). Uykunun devamlıı̆̆ının bozulduğuna dair bu bulgular diğer psikiyatrik bozukluklarda da görülen, herhangi bir psikiyatrik bozukluğa özgün olmayan bulgulardır (32). Genellikle psikolojik gerginlik ve bunun fizyolojik bağıntıları ile ilişkili artmış uyarıımışıı̆ın bir göstergesi olabileceği düşünülmektedir (32).

Çalışmada panik bozukluğu hastalarında kalp hızı değişkenleri yönünden gerek zaman gerek frekans alanında kontrol grubuna göre anlamlı bir fark saptanmamışıı. Kalp hızı değişkenliği yaş, fiziksel aktivite, kalp hastalıkları ve diyabetik nöropati gibi bedensel hastalıklardan etkilenmektedir (26). Çalısmadaki hasta grubu bedensel bir hastalığı olmayan ve genç hasta grubundan seçilmiştir. Ayrıca çevresel faktörlerin en aza indiği, otonom sinir sistemindeki tonik aktivitenin daha iyi değerlendirilebileceği uykuda çalışma yapılmışır. Uyku ile ilişkili kalp hızı değişkenliğini etkileyebilecek uyku apne sendromu ya da periyodik bacak hareketleri de mevcut değildi. Bu yönden değerlendirmeyi karıştıracak faktörler çalışmadan önce dışlanmıştır. İstirahat halinde gündüz kalp hızı değişkenliğini inceleyen ancak sınırlı sayıdaki çalışmada azalmış parasempatik aktivite gösterilmiş iken (13), diğer çalışmalarda istirahat halinde bir değişiklik gözlenmemiştir $(16,33,34)$. Bu çalışmalarda panik bozukluğu hastalarında otonomik disfonksiyonun değerlendirilmesi için istirahate göre ayakta postur veya tilt testi gibi provakasyon testlerinin daha duyarlı yöntemler olabileceği işaret edilmektedir $(8,16)$.

Gece uykuda panik nöbetleri, panik bozukluğu hastalarının yaklaşık \%15-\%45'de düzenli bir şekilde ortaya çıkan bir bulgudur. Gündüz panik ataklarının yanı sıra gece uykuda da panik atakların görülmesi hastaların uyku ile ilişkili kaygılarının artmasına ve gevşemelerine engel olur. Uykuda yapılmış kalp hızı değişkenliği çalışmalarında sadece gündüz panik nöbetleri olanlara göre gece uykuda panik nöbeti olan hastalarda göreceli

\begin{tabular}{|c|c|c|c|c|}
\hline \multirow[t]{2}{*}{ Demografik veriler } & \multirow{2}{*}{ 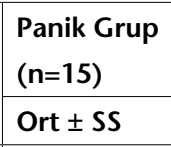 } & \multirow{2}{*}{\begin{tabular}{|l|}
$\begin{array}{l}\text { Kontrol Grup } \\
(n=15)\end{array}$ \\
Ort $\pm S S$ \\
\end{tabular}} & \multirow[t]{2}{*}{ z } & \multirow[t]{2}{*}{$p$} \\
\hline & & & & \\
\hline Yaş (yıl) & $27,0 \pm 4,5$ & $25,2 \pm 5,7$ & $-1,22$ & a.d. \\
\hline Cinsiyet (E/K) & $8 / 7$ & $6 / 9$ & - & - \\
\hline Hastalık Süresi (ay) & $2,4 \pm 1,1$ & - & - & - \\
\hline PAÖ skoru & $22,6 \pm 8,3$ & - & - & - \\
\hline \multicolumn{5}{|l|}{ Uyku Değişkenleri } \\
\hline Toplam uyku süresi (dk) & $368,6 \pm 63,9$ & $416,1 \pm 50,9$ & $-1,87$ & a.d. \\
\hline Uyku etkinliği (\%) & $84,2 \pm 11,9$ & $95,3 \pm 1,7$ & $-4,07$ & $0,001^{*}$ \\
\hline Uyanıklık sayısı & $18,1 \pm 5,2$ & $13,6 \pm 5,5$ & $-2,12$ & $0,033^{*}$ \\
\hline Uyku latansı (dk) & $18,2 \pm 19,2$ & $6,3 \pm 4,9$ & $-3,05$ & $0,002^{*}$ \\
\hline Donem $1(\%$, TUS $)$ & $4,1 \pm 1,8$ & $2,2 \pm 1,5$ & $-2,55$ & $0,011^{*}$ \\
\hline Dönem $2(\%$, TUS) & $55,4 \pm 5,9$ & $59,7 \pm 5,7$ & $-1,74$ & a.d. \\
\hline Dönem 3-4 (\%, TUS) & $19,8 \pm 5,2$ & $19,2 \pm 4,9$ & $-0,38$ & a.d. \\
\hline REM uykusu (\%, TUS) & $20,3 \pm 4,3$ & $19,2 \pm 3,8$ & $-0,65$ & a.d. \\
\hline REM latansı (dk) & $104,4 \pm 56,5$ & $100,6 \pm 23,5$ & $-0,90$ & a.d. \\
\hline
\end{tabular}




\begin{tabular}{|c|c|c|c|}
\hline KHD Değişkenleri & $\begin{array}{l}\text { Panik Grup } \\
(n=15) \\
\text { Ort } \pm S S\end{array}$ & $\begin{array}{l}\text { Kontrol Grup } \\
(n=15) \\
\text { Ort } \pm \text { SS }\end{array}$ & $\mathbf{P}$ \\
\hline SDNN (ms) & $165 \pm 71$ & $158 \pm 57$ & 0,782 \\
\hline SDANN (ms) & $87 \pm 45$ & $71 \pm 28$ & 0,303 \\
\hline RMSSD (ms) & $95 \pm 40$ & $101 \pm 38$ & 0,701 \\
\hline NN50 & $8404 \pm 5841$ & $10790 \pm 5586$ & 0,297 \\
\hline pNN50 (\%) & $25 \pm 18$ & $40 \pm 22$ & 0,061 \\
\hline KHD-Indeks & $56 \pm 98$ & $38 \pm 10$ & 0,528 \\
\hline $\mathrm{LF}\left(\mathrm{ms}^{2}\right)$ & $1,21 \pm 5$ & $1,36 \pm 5$ & 0,587 \\
\hline $\mathrm{HF}\left(\mathrm{ms}^{2}\right)$ & $1,03 \pm 5$ & $1,3 \pm 5$ & 0,337 \\
\hline $\mathrm{LF} / \mathrm{HF}$ & $1,76 \pm 0,87$ & $1,23 \pm 0,63$ & 0,092 \\
\hline
\end{tabular}

KHD: kalp hızı değişkenliği, SDNN: NN intervallerinin standart sapması, SDANN: beş dakikalık segmentlerde normal NN intervallerinin ortalamasının standart sapması, RMSSD: ardışık normal NN intervalleri arasındaki farkların karekökü, NN50: elli milisaniyeyi aşan NN intervallerinin sayısı, pNN50: elli milisaniyeyi aşan ardışık NN intervalleri arasındaki farkın yüzdesi, LF: düşük frekans gücü, HF: yüksek frekans gücü, Ort: ortalama, SS: standart sapma, * $p<0,05$.

sempatik aktivite artışının daha belirgin olduğu gözlenmiş̧ir $(18,20)$. Çalışmamızda hiçbir hastada gece uykuda panik nöbet mevcut değildi.

Çalışmada hastalık süreleri altı aydan kısa olan erken dönem hastalardan oluşmaktaydı. Kalp hızı değişkenliğinin incelendiği araştırmaların çoğunda hastalık süresi 1-8 yıl olan hastalardan oluşmaktadır $(6,8,16,18)$. Azalmış kalp hızı değişkenliği hastalık süresi ve klinik şiddet ile ilişkili olabilir (16). Çalışma grubundaki hastalarda olduğu gibi, panik bozukluğunun erken dönemi spontan panik nöbetlerle karakterizedir. Hastalığın kronikleşmesi ile panik nöbetlerin arasında beklenti anksiyetesi, durumsal panik nöbetleri, fobik kaçınma ve depresif bulguların eklendiği görülür. Hastalığın klinik şiddeti de artar. Hastalık süresi ve klinik şiddetin artması kalp hızı değişkenliğinin düşmesine neden olabilir $(14,16)$.

Bu çalışmada ilaç kullanmayan, gece uykuda panik nöbetleri olmayan, erken dönem panik bozukluğu hastalarında uyku gibi tonik otonomik aktivitenin daha sağlıklı değerlendirilebileceği istirahat durumunda sempatik hiperaktiviteyi işaret eden sempatovagal dengede bir disfonksiyon saptanmamıştır. Morbidite ve mortalite riski ile ilişkili olan azalmış kalp hızı değişkenliği, panik bozukluğunda hastalık süresi ve klinik şiddeti ile ilişkili olarak otonomik disfonksiyona yol açıyor olabilir. Bu nedenle panik bozukluğunda otonomik işlevlerin değerlendirilmesinde yaş, hastalık süresi, hastalık şiddeti ve eşlik eden patolojilerden oluşan farklı alt grupların karşılaştıııldığı araştırmalara intiyaç olduğu görünmektedir.

\section{Kaynaklar}

1. Amerikan Psikiyatri Birliği, Psikiyatride Hastalıkların Tanımlanması ve Sınıflandırılması Elkitabı, Beşinci Baskı (DSM-5), Amerikan Psikiyatri Birliği, Washington DC, 2013'den çeviren Köroğlu E, Hekimler Yayın Birliği, Ankara, 2013.

2. Charney DS, Redmond DE. Neurobiological mechanisms in human anxiety. Evidence supporting central noradrenergic hyperactivity. Neuropharmacology 1983;22:1531-6.
3. Dekker JM, Schouten EG, Klootwijk P, Pool J, Swenne CA, Kromhout D. Heart rate variability from short electrocardiographic recordings predicts mortality from all causes in middle-aged and elderly men. Am J Epidemiol 1997;145:899-908.

4. Tsuji II, Larson MG, Venditti FJ Jr, Manders ES, Evans JC, Feldman $\mathrm{CL}$, et al. Impact of reduced heart rate variability on risk for cardiac events. The Framingham Heart Study. Circulation 1996;94:2850-5.

5. Thayer JF, Lane RD. A model of neurovisceral integration in emotion regulation and dysregulation. J Affect Disord 2000;61:201-16.

6. Yeragani VK, Balon R, Pohl R, Ramesh C, Glitz D, Weinberg P, et al. Decreased R-R variance in panic disorder patients. Acta Psychiatr Scand 1990;81:554-9.

7. Yeragani VK, Pohl R, Balon R, Ramesh C, Glitz D, Jung I, et al. Heart rate variability in patients with major depression. Psychiatry Res 1991;37:35-46.

8. Yeragani VK, Pohl R, Berger R, Balon R, Ramesh C, Glitz D, et al. Decreased heart rate variability in panic disorder patients: a study of power-spectral analysis of heart rate. Psychiatry Res 1993;46:89-103.

9. Yeragani VK, Srinivasan K, Balon R, Ramesh C, Berchou R. Lactate sensitivity and cardiac cholinergic function in panic disorder. Am J Psychiatry 1994;151:1226-8.

10. Friedman BH, Thayer JF, Borkovec TD, Tyrrell RA, Johnson BH, Columbo R. Autonomic characteristics of nonclinical panic and blood phobia. Biol Psychiatry 1993;34:298-310.

11. Friedman BH, Thayer JF. Anxiety and autonomic flexibility: a cardiovascular approach. Biol Psychol 1998;49:303-23.

12. Friedman $\mathrm{BH}$, Thayer JF. Autonomic balance revisited: panic anxiety and heart rate variability. J Psychosom Res 1998;44:133-51.

13. Klein E, Cnaani E, Harel T, Braun S, Ben-Haim SA. Altered heart rate variability in panic disorder patients. Biol Psychiatry 1995;37:18-24.

14. Hamada T, Koshino Y, Misawa T, Isaki K, Gejyo F. Mitral valve prolapse and autonomic function in panic disorder. Acta Psychiatr Scand 1998;97:139-43.

15. Stein $M B$, Asmundson GJ. Autonomic function in panic disorder: cardiorespiratory and plasma catecholamine responsivity to multiple challenges of the autonomic nervous system. Biol Psychiatry 1994;36:548-58.

16. Ito $T$, Inoue $Y$, Sugihara $T$, Yamada $H$, Katayama $S$, Kawahara $R$. Autonomic function in the early stage of panic disorder: power spectral analysis of heart rate variability. Psychiatry Clin Neurosci 1999;53:667-72.

17. Yeragani VK, Sobolewski E, Igel G, Johnson C, Jampala VC, Kay J, et al. Decreased heart-period variability in patients with panic disorder: a study of Holter ECG records. Psychiatry Res 1998;78:89-99.

18. Sloan EP, Natarajan M, Baker B, Dorian P, Mironov D, Barr A, et al. Nocturnal and daytime panic attacks - Comparison of sleep architecture, heart rate variability, and response to sodium lactate challenge. Biol Psychiatry 1999;45:1313-20.

19. McCraty R, Atkinson M, Tomasino D, Stuppy WP. Analysis of twentyfour hour heart rate variability in patients with panic disorder. Biol Psychol 2001;56:131-50.

20. Aikins DE, Craske MG. Sleep-based heart period variability in panic disorder with and without nocturnal panic attacks. J Anxiety Disord 2008;22:453-63.

21. Spitzer RL, Williams JBW, Gibbon M. Structured Clinical Interview for DSM-III-R (SCID). New York State Psychiatric Institute, New York, NY. 1987.

22. Sorias S, Saygılı R, Elbi H, Nifirme Z, Mete L, Vahip S. DSM-III-R Yapılandırılmış Klinik Görüşmesi (SCID) Türkçe versiyonu: Retest ve kullanıcılar arası uyuşma ve güvenirliğin araştırılması. Ege Üniversitesi Tıp Fakültesi Dergisi 1989;2349-56.

23. Bandelow B, Hajak G, Holzrichter S, Kunert HJ, Rüther E. Assessing the efficacy of treatments for panic disorders and agoraphobia. I. Methodological problems. Int Clin Psychopharmacol 1995; 10:83-93. 
24. Tural Ü, Fidaner H, Alkın T, Bandelow B. Panik ve Agorafobi Ölçeğinin Güvenirlik ve Geçerliği. Türk Psikiyatri Dergisi 2000;11:29-39.

25. Rechtschaffen, A., Kales, A. (1968) A Manual of Standardized Terminology, Techniques and Scoring System for Sleep Stages of Human Subjects. US Government Printing Office, Washington, DC.

25. Rechtschaffen A, Kales A. (1968) A manual of standardized terminology, techniques and scoring system of sleep stages in human subjects. Los Angeles: Brain Information Service/Brain Research Institute, University of California; USA.

26. Heart rate variability. Standards of measurement, physiological interpretation, and clinical use. Task Force of the European Society of Cardiology and the North American Society of Pacing and Electrophysiology. Eur Heart J 1996;17:354-81.

27. Hauri PJ, Friedman M, Ravaris CL. Sleep in patients with spontaneous panic attacks. Sleep 1989;12:323-37.

28. Mellman T, Uhde T. Electroencephalographic sleep in panic disorder. A focus on sleep-related panic attacks. Arch Gen Psychiatry 1989;46:178-84.
29. Lydiard RB, Zealberg J, Laraia MT, M, Prockow V, Gross J, et al. Electroencephalography during sleep of patients with panic disorder. J Neuropsychiatry Clin Neurosci 1989;1:372-6.

30. Stein MB, Enns MW, Kryger MH. Sleep in nondepressed patients with panic disorder: II. Polysomnographic assessment of sleep architecture and sleep continuity. J Affect Disord 1993;28:1-6.

31. Korkmazhan H, Yetkin S, Sütcigil, Özgen F, Aydın H. Polysomnographic findings in patients with panic disorder. Gulhane Medical Journal 2010;52:237-40.

32. Benca RM, Obermeyer WH, Thisted RA, Gillin JG. Sleep and psychiatric disorders, a meta-analysis. Arch Gen Psychiatry 1992;49:651-68; discussion 669-70.

33. Garakani A, Martinez JM, Aaronson CJ, Voustianiouk A, Kaufmann H, Gorman JM. Effect of medication and psychotherapy on heart rate variability in panic disorder. Depress Anxiety 2009;26:251-8.

34. Kikuchi M, Hanaoka A, Kidani T, Remijn GB, Minabe Y, Munesue T, et al. Heart rate variability in drug-naïve patients with panic disorder and major depressive disorder. Prog Neuropsychopharmacol Biol Psychiatry 2009;33:1474-8. 